\title{
Dysplastic progression of a choledochal cyst on video cholangioscopy
}

Choledochal cysts are rare congenital cystic dilatations of the biliary tree. Surgical resection is felt to reduce the risk of malignant degeneration, which can be seen in $40 \%-60 \%$ by the fifth decade $[1,2]$. Proposed mechanisms for malignancy include reflux of pancreatic juices in the setting of an anomalous pancreaticobiliary junction (APBJ) causing chronic inflammation or bile stasis, leading to "carcinogenic" bile acid generation [3]. We present a patient with choledochal cysts where serial cholangioscopy demonstrated visual and pathologic evidence of the metaplasia to dysplasia sequence. The patient was a 47-year-old woman who had previously undergone cholecystectomy and presented with ongoing right upper quadrant pain and a dilated common bile duct on imaging, along with mild elevations in alkaline phosphatase and transaminases. Endoscopic retrograde cholangiopancreatography (ERCP) revealed retained stones and a cystically dilated distal bile duct suspi- cious for a type III choledochal cyst (choledochocele). The cyst and long common channel were consistent with APBJ and biopsies revealed intestinal metaplasia. The patient opted to undergo annual surveillance with alternating magnetic resonance cholangiopancreatography (MRCP) and cholangioscopy.

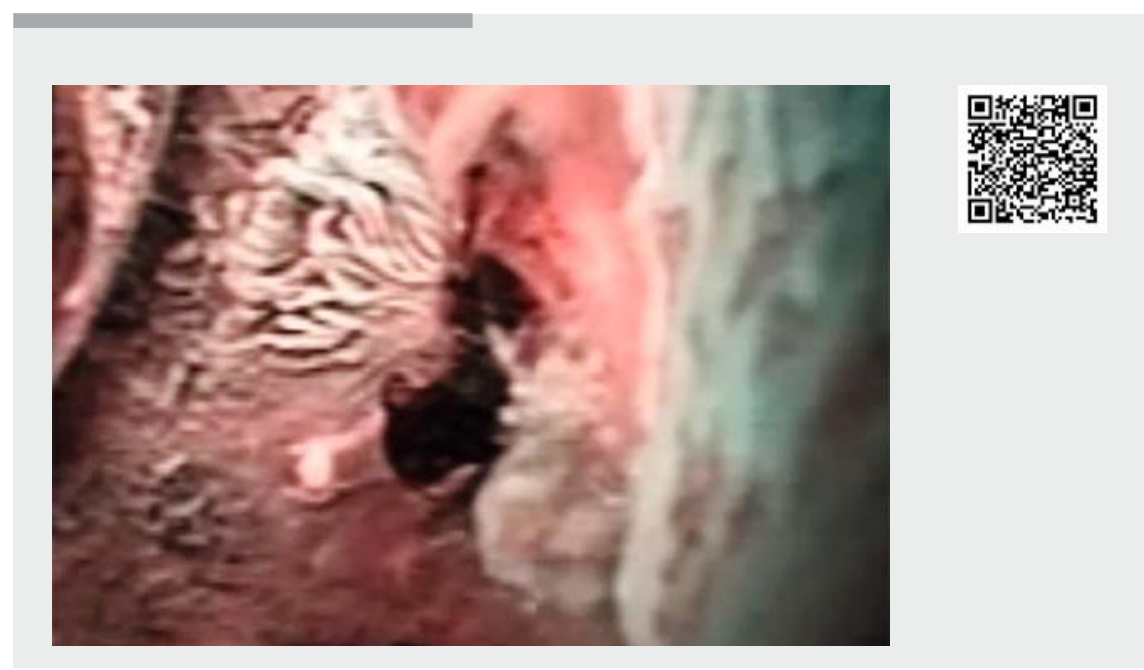

Video 1 Video cholangioscopy and confocal endomicroscopy of a choledochal cyst in a patient undergoing annual surveillance.
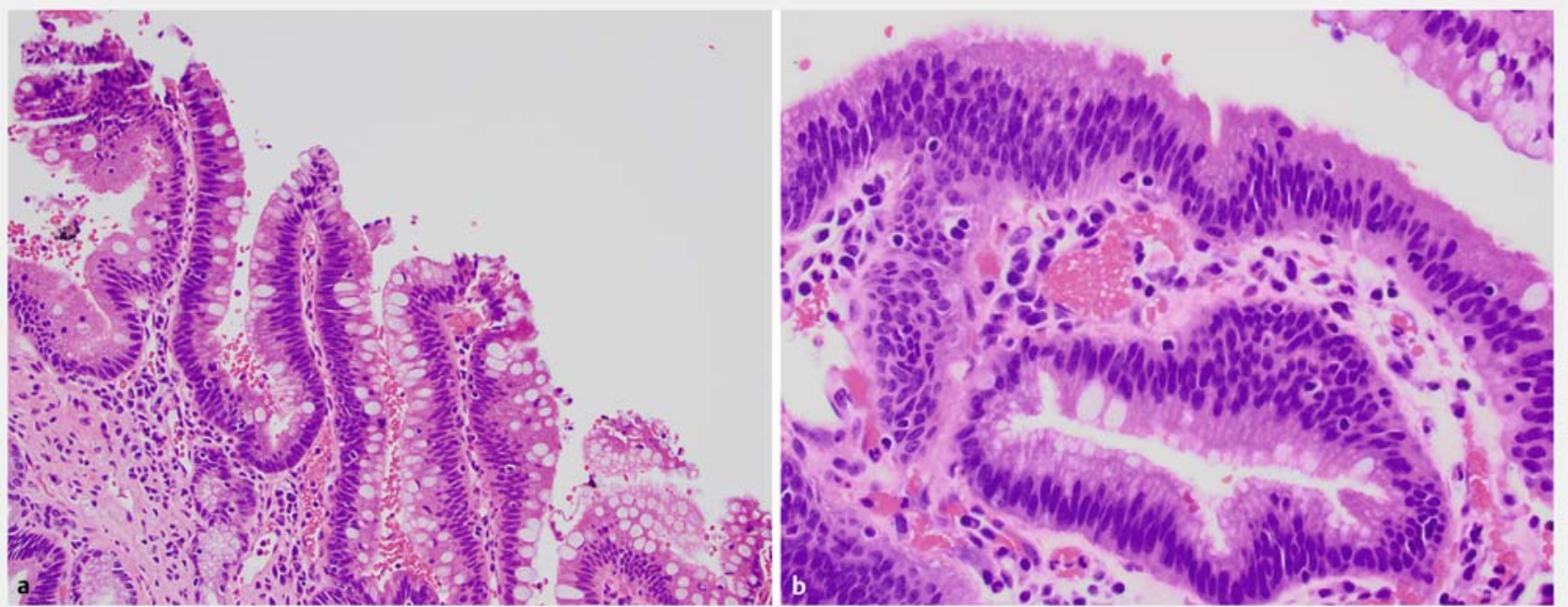

- Fig. 1 Histopathological images (hematoxylin and eosin [H\&E] stained) showing: a a representative section of the choledochal cyst in the resected specimen (magnification $\times 200$ ) with villiform mucosa lined by epithelium with a predominantly intestinal phenotype and globular mucin droplets within many of the epithelial cells that are diagnostic of intestinal metaplasia; $\mathbf{b}$ a focus of low grade dysplasia arising from a background of intestinal metaplasia within the choledochal cyst in the resected specimen (magnification $\times 400$ ), which is characterized by the loss of globular mucin droplets within the epithelium, in conjunction with hyperchromatic, elongated, pseudostratified epithelial cell nuclei. Source: Dr. Jeffrey Kaplan, University of Colorado. 
The index video cholangioscopy (Olympus XCHF-B140Y, Tokyo, Japan) showed intestinal mucosa within the cyst and pathology showed intestinal metaplasia. Repeat video cholangioscopy 2 years later (Olympus TJF-Y008/CHF 280K003) revealed "tumor vessels" and probebased confocal endomicroscopy (Cellvizio, Mauna Kea, Paris, France) demonstrated three malignant Miami criteria, including thick dark bands, dark clumps, and epithelial structures concerning for malignancy [4] ( $\vee$ Video 1 ). Biopsies demonstrated atypia but, because of the advanced imaging findings, the patient was referred for pancreaticoduodenectomy. The resected specimen revealed low grade dysplasia ( $\triangleright$ Fig. 1).

This case depicts the progression of a choledochal cyst from intestinal metaplasia to dysplasia documented by video cholangioscopy and provides further support for the aforementioned sequence of carcinogenesis in choledochal cysts. We also demonstrate suspected dysplasia by video cholangioscopy and confocal endomicroscopy that aided the decision-making process to proceed with surgery, despite non-confirmatory sampling for neoplasia.

Endoscopy_UCTN_Code_TTT_1AR_2AK

\section{Competing interests}

Raj J. Shah is a consultant and advisory board member for Boston Scientific and a consultant for Olympus and Cook Medical. The remaining authors declare that they have no conflict of interest.

The authors

Benjamin Warren, Samuel Han, Raj J. Shah Division of Gastroenterology and Hepatology, University of Colorado Anschutz Medical

Campus, Aurora, Colorado, USA

\section{Corresponding author}

\section{Raj J. Shah, MD}

Division of Gastroenterology and Hepatology, University of Colorado Anschutz Medical Center, 1635 Aurora Ct, Mail Stop F735, Rm. AIP 2.031, Aurora, CO 80045, USA Fax: +1-720-848-2757

Raj.Shah@cuanschutz.edu

\section{References}

[1] Katabi N, Pillarisetty VG, DeMatteo R et al. Choledochal cysts: a clinicopathologic study of 36 cases with emphasis on the morphologic and the immunohistochemical features of premalignant and malignant alterations. Hum Pathol 2014; 45: 2107-2114

[2] Søreide K, Søreide JA. Bile duct cyst as precursor to biliary tract cancer. Ann Surg Oncol 2007; 14: 1200-1211
[3] Reveille RM, Van Stiegmann G, Everson GT. Increased secondary bile acids in a choledochal cyst. Possible role in biliary metaplasia and carcinoma. Gastroenterology 1990; 99 : 525-527

[4] Meining A, Shah RJ, Slivka A et al. Classification of probe-based confocal laser endomicroscopy findings in pancreaticobiliary strictures. Endoscopy 2012; 44: 251-257

\section{Bibliography}

Endoscopy 2021; 53: E285-E286

DOI 10.1055/a-1252-2040

ISSN 0013-726X

published online 8.10 .2020

(c) 2020. Thieme. All rights reserved.

Georg Thieme Verlag KG, Rüdigerstraße 14,

70469 Stuttgart, Germany

\section{ENDOSCOPY E-VIDEOS}

https://eref.thieme.de/e-videos

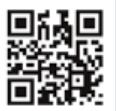
Endoscopy E-Videos is a free access online section, reporting on interesting cases and new techniques in gastroenterological endoscopy. All papers include a high quality video and all contributions are freely accessible online.

This section has its own submission website at https://mc.manuscriptcentral.com/e-videos 